\title{
ONCOLOGY NURSING CARE STANDARDS
}

\author{
Astrid M de Kleijn and Marie E Muller
}

\section{INTRODUCTION}

Oncology is the study of malignant neoplastic diseases generally referred to as cancer (Baldonado \& Stahl, 1982: 1). Oncology nursing is the nursing of patients suffering from some form of neoplastic pathology. As a disease, cancer has been known thoughout recorded history. Hippocrates himself ibed many types of neoplasm and he probably coined the term carcinoma (Kahn, Love, Shermand \& Chakravorty, 1983: 3). Until the late 1950 's, because of the apparently incurable nature of the disease, a diagnosis of cancer was viewed by both the patient and health care provider, as a death sentence. However, advances in surgical techniques, radiation therapy, chemotherapy and immunotherapy have greatly altered prognoses for the better. Today it is estimated that $40 \%$ of diagnosed neoplasms are curable and $15 \%$ of the remaining have a life expectancy greater than 15 years (Dietz, 1981: 3).

Therapy, however, may cause primary and/or secondary disabilities and the patient is exposed to many difficulties. Not only is his future unpredictable but the methods of treatment used to alleviate his condition are often very toxic and may induce a variety of unpleasant side effects a toblems. Most patients receive a course of chemotherapeutic drugs and/or radiation therapy as part of their treatment regimen. Successful therapy depends upon meeting the individual needs and carrying out evaluation of the quality of care on an ongoing basis. This evaluation of the quality should take into consideration the potential course and outcome of the disease (Dierz, 1981: 172-173).

The oncology nurse plays an important role in the multiprofessional treatment regimen and is accountable for rendering quality nursing care. Nurses are, however, unable to objectively and formally evaluate the quality of oncology nursing care due to a lack of standards and evaluation instruments in this regard. Standards guide the nursing practice and will help to monitor the quality of nursing care rendered in the oncological nursing unit.

The purpose of this study is to formulate oncology nursing care standards for a particular hospital.

\section{Abstract}

Oncology nursing as a specialised nursing discipline has no published nursing care standards for South Africa. The purpose of this study was to formulate oncology nursing standards for a particular research hospital. A specific approach was used and the oncology nursing experts in the research hospital compiled and formulated the standards. Group discussions and critical debating of the standards followed. The standards were ratified by means of verbal consensus between the experts and professional nurses in the oncology unit. These standards could serve as a guide to ensure quality oncology nursing care. National validation of the standards is recommended.

\section{Uittreksel}

Onkologiese verpleging, as 'n gespesialiseerde verpleegdissipline, het geen formeel-gepubliseerde verpleegstandaarde in Suid-Afrika nie. Die doel van hierdie studie was om onkologiese verpleegsiandaarde vir ' $n$ spesifieke navorsingshospitaal te formuleer. 'n Spesifieke benadering ten opsigte van standaardformulering is gewlg. Kundiges in die hospitaal het standaarde saamgestel en geformuleer. Groepbesprekings en kritiese debatvoering het gevolg. Die standaarde is by wyse van verbale konsensus deur die kundiges en professionele verpleegkundiges in die onkologie verpleegeenheid bekragtig. Hierdie standaarde behoort as riglyn te dien vir gehalteverpleging in hierdie verband. Nasionale validering van die standaarde word aanbeveel.

\section{LITERATURE REVIEW}

Oncology nursing care is a multifaceted speciality which deals with patients who may be at any point on the health-illness continuum ranging from the high risk patient needing information about prevention to the patient needing comfort and support during dying. Few medical diagnoses convey so dramatically and unambiguously the spectre of death as does cancer. From the moment of detection and diagnosis, the certainty of mortality influences the behaviour of both the patient and the medical care team. Consequently it is important that those involved in patient treatment and support examine their own attitudes toward cancer and death before attempting to care for others (Portlock \& Goffinet, 1986: 295). Oncology nursing care therefore requires special nurses.

The professional responsibilities of a registered nurse are embodied in the South African Nursing Council (1984) regulation relating 10 the scope of practice of persons who are registered or enrolled under the Nursing Act (RSA, 1978).

The registered nurse is responsible for scientifically based physical, chemical, psychological, social, educational and technological nursing care. This therefore requires specialised knowledge on the part of the nursing staff in an oncology nursing unit and meeting the basic health needs of the oncology patient becomes a specialised area of nursing

The professional responsibilities also include preventive, promotive, curative and rehabilitative aspects of nursing care and the recognition of the patient as part of a family and a community. The acts and interventions the nurse is expected to perform ensure that the patient is nursed in totality with his physical, social and psychological needs being met. The professional nurse is responsible too for the specific nursing care of patients at high risk, in this case the patient suffering from cancer. The objective of the health team is the rehabilitation of the patient, back into family and community life. In order to maintain control of their lives, many cancer patients need to change their habits, modify their normative prescribed social roles, redefine and reinterpret basic concepts such as health and iilness. Thus the nurse's objectives are to assist the patient to adjust to different ways of meeting his daily requirements, establishing new techniques of self care, modifying self-image, revising his routine of daily living, and developing a new life-style compatible with the effects of any disabilities (Dietz, 1981: 170).

On respecting the right of the patient to self-determination, his involvement in the 
planning and implementation of a nursing care programme is of paramount importance. The patient has the right to give informed consent regarding all medical and nursing interactions (Given \& Given, 1984: 146).

In assessing the patient's health needs and problems, the nurse should take into consideration his lifestyle, history, cultural background and self-care performance. The patient's abilities and disabilities which will determine the extent of his engagement in self-care activities should also be assessed (Given \& Given, 1984: 140). Problems most commonly experienced by the oncology patient are nutritional, psychological and comfort (pain) starus, potential for infection and injury, knowledge of the disease process and the implications of the treatment modalities, as well as the ability to carry out activities necessary for daily living (Cox \& Wark, 1980: 109-132).

The progressive anorexia-cachexia accompanying advanced malignancy may be a major source of morbidity. Cachectic patients are often unable to tolerate the complications of cancer therapy and are more susceptible to infections (Pruitt, 1983: 370; Smith, 1975: 53). Fever as a manifestation of malignant disease may present a difficult diagnostic problem. While at least two-thirds of all cancer patients will have fever at some time during their iilness, in most instances this symptom is attributable to infection (Porlock \& Goffinett, 1986: 37). It is therefore important to undertake a comprehensive patient history and physical examination regarding the patient's physical, social and psychological status.

Nursing a patient in totality implies that the psychological needs of the patient are being met. The importance of this aspect is highlighted in the SANC(1984) regulation: "monitoring of the patient's reaction to disease conditions, trauma, stress, anxiety, medication and treatment." and the patient may experience certain emotional stages such as denial, anger, bargaining, depression and acceptance. Besides the fear of dying, patients feat pain and body disfigurement. The patient's psychological response to body disfigurement depends upon his self-concept and body image, which are uniquely personal, social, emotional and psychological (Baldonado \& Stahl, 1982: 134-147).

In assessing psychological status, the oncology nurse therefore needs to identify the patient's and family's coping mechanisms and meeting these needs requires a multi-professional team approach (Maguire, 1978: 33).

The relationship between patient and care-giver should be open, honest, and based on trust. Goals of treatment should be realistic, recognising that both quality and quantity of survival are important. Whatever therapy is chosen, the patient must be informed not only of its potential benefits but of its potential hazards as well. Although the patient may be anxious to begin treatment, he will also be reluctant to suffer its side effects. Communication, accessibility, and consistent support assist in lessening this ambivalence. For those patients who are cured, stress and anxiety do not end with the completion of treatment but may be present continuously for many years to come. For those whose disease recurs or who cannot be cured, there is a persistent confrontation with mortality. Care-givers should bear in mind such fundamental features of human worth as respect for the individual, inclusion in a community, concern for the physical body, and personal meaning beyond the self (Portlock \& Goffinet, 1986: 295).

Main physical problems to be considered are pain, nutritional status, haemoptysis, pleural effusion, pericardial effusion, hepatic metastases, bowel obstruction, renal failure, bone metastases, and viral/fungal infections. Pain in a patient with cancer may be due to benign, unrelated causes, may be referted, and may be very difficult to control. The patient also needs to cope with fear, anxiety and depression of chronic pain (Portlock \& Goffinet, 1986: 297; Cox \& Wark, 1980: 109-132; Hauck, 1986: 67)

Effusions may affect pulmonary and/or cardiac function which require many local, systemic or surgical therapeutic interventions. Metastases can result in severe pain and other complications increasing the mortality rate. Bowel obstruction is one of the most common gastrointestinal problems resulting in abdominal pain, emesis, and abdominal distention. Infection is a common complication. As one of the side effects, chemorherapy causes a decrease in the leucocyte count. This increases the potential for infection. Another cause of leucopenia is metastatic involvement of the bone marrow (Portlock \& Goffinet, 1986: 295-321; Speechley, 1985: 21-22). There is also a potential for injury. Thrombocytopenia is usually chemotherapy induced or as the result of bone martow metastasis and will cause haemorrhage. The nurse's role is confined mainly to early detection, by daily physical examination of the patient as well as testing faeces and urine for occult blood (Pruitt 1983: 374).

There are many specific problems related to specific cancer diagnoses. Specific signs and symptoms need to be detected by the nurse, for example excessive bleeding, offensive discharges, etc. The side effects of chemotherapy and radiation should be monitored and appropriately addressed. Surgical interventions may lead to ostomies which also require special nutsing care. Radiation therapy may cause acute skin reactions, cardiopulmonary complications, gastrointestinal problems, and specific organ complications. Chemotherapy causes acute and chronic toxicities of which nausea and vomiting are most common and must be addressed appropriately (Portlock \& Goffinet, 1986: 254-263).

Oncology nursing care is a specialised discipline requiring very special nurses. Oncology patients receive quality nursing care when the nurse rendering that care adheres to the scientific principles of diagnosing the patients' health needs and problems, formulating and implementing an appropriate nursing care plan and evaluating the effectiveness of her nursing interactions. The patient's response to the treatment modality is dependent upon such variables as the cancer diagnosis, the stage of the disease, health history, socio-economic status and motivation. Malignant diseases prevail in all organs and systems of the body and therefore the oncology nurse needs to be a specialist in all the different types of cancer.

\section{DEFINITION OF TERMINOLOGY}

\section{Oncology nursing care}

Oncology nursing care is the nursing of patients suffering from cancer and may be curative, restorative, palliative or supportive, depending upon the medical diagnosis of the patient.

\section{Standard}

A standard is a descriptive statement of the expected level of performance against which the quality of oncology nursing care can be evaluated.

\section{RESEARCH METHODOLOGY}

A descriptive approach was followed whereby the domain variables related to oncology nursing care were explored, described and validated. A literature review was undertaken to ensure theoretical and content validity of the standards. American and British literature was urilised to identify the prerequisites of qua oncology nursing care. A specitic approachm standard formulation was utilised, focusing on the needs of a particular health institution.

The research hospital utilised in this study is the referral hospital for the Southern Transvaal for black patients requiring special ist oncology care and is also a training hospital for the post-basic course in oncology nursing science.

In this contextual study the target population for the formulation of oncology nursing care standards were oncology nursing care specialists working in the research hospital. Clinical nurse specialists were selected purposefully according to their professional qualification in Oncology Nursing Science, as well as their experience in oncology nursing care. These clinical specialists served on a committee to formulate and validate the standards. All commirtee members were nurses employed at the research hospital and consisted of the following members:

- a clinical nurse educator for the post basic course of Oncology Nursing Science; 
- two chief professional nurses in charge of oncology wards in the hospital;

- two senior professional nurses who had at least two years experience in specialised oncology nursing care;

- rwo professional nurses who had at least two years experience in specialised oncology nursing care.

All the committee members held the post-basic registration of the South African Nursing Council in Oncology Nursing Science.

The committee members were requested to formulate standards and criteria for oncology nursing care. They held weekly discussions for three months. Through group discussions and by reaching verbal consensus, standard care plans were drawn up for the common treatment modalities and medical diagnoses of patients nursed in the oncology wards. The formulated standard care plans were circulated among other tered nurses in oncology wards for their consideration and input and ratification and validation of standards was done verbally by these nurses.

From these standard care plans the committee members identified the patient problems that required the same nursing interventions. These problems were grouped together and formulated according to the scientific method of nursing care, namely assessment, nursing diagnosis, planning, implementation and evaluation. The terminology appearing on the standardised provincial nursing records was incorporated in the wording of the standards and criteria so as to prevent confusion.

No standard of nursing care was accepted by the committee unless full verbal consensus was reached among members and unless it was accepted by the registered nurses in the -logy wards. Standards and criteria were a.sidered and debated according to their appropriateness/applicability, completeness and clarity, as well as their realistic usefulness in the unit.

The final standards and criteria therefore had content validity based upon the literature and ratified by domain special ists/experts.

\section{RESULTS}

The following standards and criteria were formulated:

1. A comprehensive patient history and physical examination is done for every patient. The assessment includes:

1.1 A patient interview regarding:

- chief complaint

- history of present illness

- allergies

- medications

- past medical history

- cultural environmental and socioeconomic conditions
- basic health needs/activities of daily living

- food and fluid preferences

- appetite changes/weight changes

1.2 Psychological assessment regarding:

- emotional status

- concerns during hospitalisation

1.3 Physical assessment regarding:

- physical status

- nutritional status

- personal hygiene and grooming

- organ/systemic dysfunction

1.4 Assessment regarding personal perception of illness

- type of illness

- severity and prognosis

1.5 The data for the comprehensive patients history is obtained from all available sources:

- patient and/or family

- health care providers

- medical practitioner(s) reports

* laboratory reports

1.6 The data are collected using a scientific methodology:

- interview

- observation and inspection

- examination: palparion/auscultation

- reports and records

1.7 The data gathered are organised systematically:

- provincial records utilised

- details completed fully

1.8 The patient's history and physical examination is done within $\mathbf{4 8}$ hours of admission.

2. Nursing diagnosis is made and recorded and accompanied by an appropriate nursing care plan:

2.1 The present and potential problems are identified and recorded.

2.2 The extent and intensity of the problem(s) experienced, as well as the exact location, character and duration are described.

2.3 The underlying causes are identified and the data base recorded.

2.4 The most common problems experienced are assessed and appropriately addressed.

2.4.1 General care regarding:

- pain

- weight loss

- presence of infection: local or systemic

- pal pable mass or lymph mass

- limited mobility
- malaise

- haematological dysfunction

- psychological status

2.4.2 Side effects of chemotherapy:

- gastrointestinal dysfunction

- extravasation

- inflamation of mucosa

- haematological dysfunction

2.4.3 Side effects of radiation therapy:

- skin reactions

- alopecia

- gastrointestinal dysfunction

- haematological dysfunction

2.4.4 Specific problems:

- breast carcinoma: dyspnoea head and neck tumours: mucal reaction;

- glossitis; throat infection; dental carries.

- cervical carcinoma: offensive discharge; vaginal bleeding; dysuria; incontinence of urine and faeces condylomata.

- other cancer problems

2.5 The patient/family agree with the nurse as to what the desired outcomes should be.

2.6 The formulated desired outcomes are congruent with the patient's problems and the established objectives which are to restore the patient's optimal functioning capabilities and/or to ensure a peaceful death, and therefore focus on:

- enabling the patient to function comfortably within the limitations due to cancer;

- controlling the symptoms;

- improving the nutritional status of the patient;

- enabling the patient to cope with the illness;

- enabling the patient to understand the nature of the disease, the chosen treatment plan and care;

- ensuring the the patient experiences minimal discomfort or complications from the chosen treatment;

- ensuring that the patient is knowledgeable about self care and resources for continuity of care.

2.7 The desired outcomes are consistent with other heal th provider's expectations. Cognisance is therefore taken of the patient's medical prognosis.

2.8 The desired outcomes are measurable within a certain time frame and specifically stated.

3. The nursing care plan is implemented effectively including the following:

- the patient and family are actively involved;

- the actions are consistent with the nursing prescriptions:

- the actions are flexible and individualised for each patient; 
- the actions include principles of safery and infection control;

3.1 The prescribed nursing actions:

- are specific to the identified patient problems and desired outcomes;

- are based on current scientific knowledge;

- incorporate principles of patient teaching;

- incorporate principles of psychological interactions;

- incorporate environmental factors influencing the patient's health;

- include human, material and community resources;

- include keeping patient knowledgeable of health status and total health care plan.

3.2 The prescribed actions focus on specific cancer related problems:

\subsubsection{Pain:}

- teaching patient how to use the pain chart to inform nurses of site and intensity of pain, as well as the effectiveness of prescribed analgesics;

- together with the patient decide on the best combination of analgesics and sedatives for pain relief;

- listening to patient and allowing to express tears;

- utilising diversional pain therapy;

- collaborating with medical practitioners and other health professionals to revise pain treatment;

- monitoring vital signs that will indicate pain or complications of pain treatment.

\subsubsection{Weight loss:}

Promote optimum food and fluid intake by:

- assisting patient to eat well balanced meals within diet, considering patient's condition and preferences;

- provide for flexibility of menus and timing of meals;

- reduce nausea-stimulating factors;

- with patient/family identify nausea-therapy methods;

- refer a dietician to teach/inform patient/family regarding diets;

- suppor parient by answering questions;

- weigh patient according to needs;

- participate in plan for special feeding regimens;

\subsubsection{Infection:}

\subsubsection{Wound infection:}

* dress wound(s) as fequently as required;

- teach patient or relatives the necessary wound care techniques;

- support patient by giving relevant information

- assess wound healing or non-healing;

- take part in deciding upon altemative wound care regimens;

- monitor temperature according to individual needs.
3.2.3.2 Systemic infection:

- monitor any signs and symptoms of systemic infection;

- utilise the most appropriate techniques of lowering body temperatures;

- initiate isolation procedures/nursing when appropriate;

- obtain blood, sputum, urine and other samples for culture when appropriate;

- administration of prescribed antibiotics and monitoring of possible side effect;

- educate patient regarding personal hygiene.

3.2.4 Palpable lymph nodes or mass:

- re-inforce medical pratitioner's explanation of iliness and treatment

- explain/answer questions regarding diagnostic procedures;

- explain/answer questions regarding the outcome of diagnostic studies done to determine baseîne data and metastatic disease, as weil as the frequency and purpose of repeating procedures/ studies;

- explain the course of treatment(s);

- assess level of understanding;

- if a limb is affected institute the appropriate nursing regimen to alleviate pain, swelling, pressure and complications.

\subsubsection{General malaise:}

- determine the patient's current capabilities;

- establish a rest/activity programme in accordance with the patient's needs, limitations and tolerance level;

- provide assistance and supervision as necessary to achieve the appropriate level of functioning;

- encourage family participation in the programme

- provide an environment and measures conducive to rest and relaxation;

\subsubsection{Haematological dysfunction:}

- determine the exact aetiology;

- obtain blood laboratory results;

- a bed rest nursing regimen is implemented

- assist patient in maintaining personal hygiene;

- assist patient in activities of daily living;

- assess and monitor any signs and symptoms of intratissual bleeding;

- examine urine, faeces, vornitus and sputum for any visible blood;

- explain/answer questions pertaining to disease process;

- assess the patient's level of understanding,

- institute a patient/family teaching programme to $\mathrm{prevent} / \mathrm{minimise}$ trauma;

- prevent possible systemic infection by a reverse barrier nursing regimen;

- administer prescribed antibiotics and monitor for possible complications or side effects;
- take any precautionary measures to prevent potential complications, eg when using a Hickman line.

3.2.7 Psychological effects

- assess whether the patient and 'or family are in a grieving phase;

- accept the patient's response and emphathise appropriately;

- establish a trust relationship;

- identify resource persons:

- allow family and patient as much time together as desired;

- assist patient to cope with body image changes:

- encourage participation in self care;

- facilitate interaction with other patients undergoing similar therapy, if appropriate;

- assure continued support regardless of patient's decision about therapy;

- give positive reinforcement and realistic hope about progress;

3.2.8 Chemotherapy:

- reinforce physician's explanation of disease, treatment and prognosis;

- clarify with patient/family the aims of chemotherapy;

- explain types of drugs administered, frequency and possible side effects:

- explain all procedures and special care required;

- collaborate with physician and appropriate resource people to manage treatment and its effects at home;

- provide and teach measures to preven or control side effects: nausea and vomiting; loss of appetite; stomatitis weakness and fatigue; chills and fever alopecia; gastrointestinal ulceration and/or bleeding; diarthoea and constipation; skin changes myelosuppression; infection extravasation

- take measures to preserve the veins on patients who require frequent invar procedures;

- plan discharge with patient and family;

- extravasation: monitor blood flow; signs and symptoms of infiltration instruct patient to report buming/pain at site;

\subsubsection{Radiation therapy:}

- explain/answer questions and listen to concerns about pre-therapy preparation:

- reinforce patients' and family's understanding of aims of therapy;

- provide general measures for patient undergoing radiation therapy;

- discuss/explain possible side effects;

- discuss and explain the patient's responsibilities;

- stress importance of preventive measures at beginning, during and after course of therapy;

- initiate measures to control nausea and vomiting;

- promote optimum food and fluid intake;

- institute measures to maintain skin integrity;

- assist patient who has alopecia 
- intervention in the critical areas of patient care related to specific treatment sites.

4. The nursing care regimen is continually evaluated and revised according to the changes in the patient's healtb status.

4.1 The data are collected to assess whether specific desired outcomes have been achieved.

4.2 The collected data are compared with the stated desired outcomes.

4.3 The parient/family and nurse(s) evaluate the achievement of stated desired outcomes.

4.4 All data concerning the patient's progress and nursing interventions are recorded.

4.5 The nursing care regimen is reviewed and modified according to the patient's needs.

1.6 The patient profile is updated as new information is received.

\section{CICLUSION AND RECOMMENDATIONS}

Local oncology nursing care standards were formulated and validated by oncology clinical zare experts employed by the research hospital. These standards can serve as a guide to improve the quality of oncology nursing care in this hospital and can be used for the development of an evaluation instrument in this regard.

National validation of the standards is recommended to prove statistically the validity of the standards.

\section{REFERENCES}

BALDONADO AA \& STAHL AD 1982: Cancernursing; 2nd ed. New York: Medical examination.

COX S \& WARK E 1980: The delivery of nursing care: oncology for nurses and heal th care professionals. London: $G$ Allen \& Unwin.

DIETZ JH 1981: Rehabilitation oncology. New York: J Wiley \& Sons.

GIVEN BA \& GIVEN CW 1984: Creating a climate for compliance. Cancer Nursing, 7(2), April, 1984: 139-147.

HAUCK SL 1986: Pain: problem for the person with cancer. Cancer Nursing, 9(2), April, 1986: 66-76.

KAHN SB LOVE RR SHERMAND C \& CHAKRAVORTY R 1983: Concepts in cancer medicine. New York: Grune \& Stratton.

MAGUIRE P 1978: The psychological effects of cancer and their treatment: oncology for nurses and health care professionals. London: G Allen \& Unwin.

PORTLOCK CS \& GOFFINET DR 1986: Manual of clinical problems in oncology; 2nd ed. Boston: Little Brown.

PRUITT BT 1983: Supportive care: concepts in cancer medicine. New York: Grune \& Stratton.
SMITH EA 1975: A comprehensive approach to rehabilitation of the cancer patient. New York: McGraw Hill.

SPEECHLEY $V$ 1985: The chemotherapy challenge. Nurse's role in the intravenous administration of cytotoxic drugs. Nursing Mirror, 161(4), July 24, 1985: 21-22.

SOUTH AFRICAN NURSING COUNCIL 1984: R2598, as amended. Regulations relating to the scope of practice of persons who are registered or enrolled under the Nursing Act, No 50 of 1978 . Pretoria: Government printing office.

REPUBLIC OF SOUTH AFRICA 1978: Nursing Act, No 50 of 1978. Pretoria: Government printing office.

\section{Acknowledgments}

The authors acknowledge the contribution of the oncology registered nurses of the Hillbrow hospital. The researcher wishes to thank the Rand Afrikaans University for a bursary which made this study possible.

This article is based upon research conducted for the degree M.CUR. (Nursing management) at the Rand Afrikaans University.

\begin{tabular}{c} 
AstridM de Kleijn \\
M.CUR. (RAU) \\
Hillbrow Hospital \\
Senior Nursing Service Manager \\
Marie E Muller \\
D.CUR. (RAU) \\
RandAfrikaans University \\
Associate Professor \\
\hline
\end{tabular}

